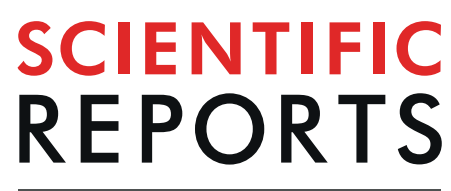

natureresearch

\title{
Performance Differences of Hexavalent Chromium Adsorbents Caused by Graphene Oxide Drying Process
}

\author{
JinHyeong Lee ${ }^{1,2,6}$, Hee-Gon Kim ${ }^{2,3,6}$, Jung-Hyun Lee ${ }^{2}$, So-Hye Cho ${ }^{1,4}{ }^{4}$ Kyung-Won Jung ${ }^{3}$, \\ Seung Yong Lee ${ }^{1,4^{*}}$ \& Jae-Woo Choi ${ }^{3,5^{*}}$
}

In this study, the influence of drying conditions on amine $\left(-\mathrm{NH}_{3}\right)$ functionalization of graphene oxide (GO) was evaluated, and the hexavalent chromium $(\mathrm{Cr}(\mathrm{VI}))$ adsorption efficiency of the prepared materials was compared. 3-[2-(2-aminoehtylamino) ethylamino]propyl-trimethoxysilane ( $3 \mathrm{~N})$ was used for amine functionalization. The synthesized materials were analyzed by SEM, BET, TGA, XPS, and EA. TGA results showed that the solution-GO (SGO) was functionalized by more $3 \mathrm{~N}$ molecules than freezedried GO (FDGO) and oven-dried GO (ODGO). Additionally, XPS analysis also showed that the ratio of $\mathrm{N} / \mathrm{C}$ and $\mathrm{Si} / \mathrm{C}$ was relatively high in $\mathrm{SGO}$ than FDGO and ODGO. The maximum adsorption capacity of SGO, FDGO, and ODGO for Cr(VI) was $258.48,212.46$, and $173.45 \mathrm{mg} \mathrm{g}^{-1}$, respectively. These results indicate that it is better to use $\mathrm{SGO}$ without drying processes for efficient amine functionalization and $\mathrm{Cr}(\mathrm{VI})$ removal. However, when the drying process is required, freeze-drying is better than oven-drying.

The active development in various industrial sectors, such as textile, metal finishing, leather tanning, stainless steel, and electroplating ${ }^{1-7}$ contribute to the discharge of contaminated wastewater containing inorganic (heavy metals, phosphates, nitrates, sulfates, etc.), organic (phenols, dyes, pesticides, pharmaceutical compounds, etc.), and biological (bacteria, viruses, etc.) compounds. Among these, heavy metals such as chromium (Cr), arsenic $(\mathrm{As})$, copper $(\mathrm{Cu})$, lead $(\mathrm{Pb})$, cadmium $(\mathrm{Cd})$, and mercury $(\mathrm{Hg})$ are typical toxic substances that exist as cations and anions in water ${ }^{8}$. Chromium exists in two stable oxidation states, which are the hexavalent chromium $(\mathrm{Cr}(\mathrm{VI}))$ and trivalent chromium $(\mathrm{Cr}(\mathrm{III}))$ variants ${ }^{9}$. While $\mathrm{Cr}(\mathrm{III})$ is minimally toxic, $\mathrm{Cr}(\mathrm{VI})$ is highly toxic and causes significant environmental damage ${ }^{10}$. Further, $\mathrm{Cr}(\mathrm{VI})$ can cause carcinogenesis and mutations in humans. For these reasons, the World Health Organization (WHO) regulates the concentration of $\mathrm{Cr}(\mathrm{VI})$ in drinking water to less than $50 \mathrm{ng} \cdot \mathrm{L}^{-111}$. To comply with this rigorous and necessary regulation, the application of water treatment techniques that can remove low concentrations of $\mathrm{Cr}(\mathrm{VI})$ is required. Various techniques, such as, redox, ion-exchange, adsorption, membrane filtration, and the like $\mathrm{e}^{12-16}$ are applied according to the purpose. However, the removal of low concentrations of $\mathrm{Cr}(\mathrm{VI})$ with most of these wastewater treatment systems is highly challenging. Among these approaches, adsorption is more effective for $\mathrm{Cr}(\mathrm{VI})$ removal since adsorbents are eco-friendly and not generating by-products ${ }^{17}$. Therefore, we conducted further research on advancing adsorption technology for the removal of $\mathrm{Cr}(\mathrm{VI})$ from wastewater. For the first time, in this study, we developed an adsorbent based on graphene oxide (GO) and evaluated its $\mathrm{Cr}(\mathrm{VI})$-adsorption performance.

GO has been used in various fields such as electronic, biological, and physical applications ${ }^{18}$ owing to its several advantages, such as straightforward synthesis, good solution stability, and the large surface-area-to-volume ratio $^{19-21}$ and small weight-to-volume ratio. Particularly, the rich oxygen-containing surface functional groups

\footnotetext{
${ }^{1}$ Materials Architecturing Research Center, Korea Institute of Science and Technology, Hwarang-ro 14-gil 5, Seongbuk-gu, Seoul, 02792, Republic of Korea. ${ }^{2}$ Department of Chemical and Biological Engineering, Korea University, 145 Anam-ro, Seongbuk-gu, Seoul, 02841, Republic of Korea. ${ }^{3}$ Water Cycle Research Center, Korea Institute of Science and Technology, Hwarang-ro 14-gil 5, Seongbuk-gu, Seoul, 02792, Republic of Korea. ${ }^{4}$ Division of Nano \& Information Technology, KIST school, Korea University of Science and Technology, Hwarang-ro 14-gil 5, Seongbuk-gu, Seoul, 02792, Republic of Korea. ${ }^{5}$ Division of Energy \& Environment Technology, KIST school, Korea University of Science and Technology, Hwarang-ro 14-gil 5, Seongbuk-gu, Seoul, 02792, Republic of Korea. ${ }^{6}$ These authors contributed equally: JinHyeong Lee and Hee-Gon Kim. *email: patra@kist.re.kr; plead36@kist.re.kr
} 


\begin{tabular}{|l|l|l|l|}
\hline Adsorbents & GO drying process & Contaminants & Ref. \\
\hline Aminosilane-GO & No drying - solution & $\mathrm{Cr}(\mathrm{VI})$ & 28 \\
\hline DCTA/E/GO & No drying & $\mathrm{Cr}(\mathrm{VI})$ & 35 \\
\hline PAS-GO & Freeze-drying & $\mathrm{Pd}(\mathrm{II})$ & 36 \\
\hline PAM-g-graphene & Freeze-drying & $\mathrm{Pb}(\mathrm{II})$ & 37 \\
\hline TOA-EGO & $\begin{array}{l}\text { Vacuum-oven-drying at } \\
\text { room temperature }\end{array}$ & $\mathrm{Cr}(\mathrm{VI})$ & 38 \\
\hline SAGO & $\begin{array}{l}\text { Vacuum-oven-drying at } \\
\text { room temperature }\end{array}$ & $\mathrm{Cu}(\mathrm{II}), \mathrm{Pb}(\mathrm{II})$ & 39 \\
\hline AMGO & Oven-drying at $30^{\circ} \mathrm{C}$ & $\mathrm{Cr}(\mathrm{VI})$ & 15 \\
\hline PPy/GO & $\begin{array}{l}\text { Vacuum-oven-drying } \\
\text { at } 40^{\circ} \mathrm{C}\end{array}$ & $\mathrm{Cr}(\mathrm{VI})$ & 40 \\
\hline IT-PRGO & $\begin{array}{l}\text { Vacuum-oven-drying } \\
\text { at } 60^{\circ} \mathrm{C}\end{array}$ & $\mathrm{Hg}(\mathrm{II})$ & 41 \\
\hline PPy-GO & Oven-drying at $60^{\circ} \mathrm{C}$ & $\mathrm{Cr}(\mathrm{VI})$ & 42 \\
\hline Aminosilane-GO & Oven-drying at $100^{\circ} \mathrm{C}$ & $\mathrm{Cr}(\mathrm{VI})$ & 43 \\
\hline Chitosan/GO & $\begin{array}{l}\text { Drying under } \\
\text { unspecified condition }\end{array}$ & $\begin{array}{l}\mathrm{Cu}(\mathrm{II}), \mathrm{Pb}(\mathrm{II}), \\
\mathrm{Cr}(\mathrm{VI})\end{array}$ & 24 \\
\hline TGOCS & Not mentioned & $\mathrm{Cr}(\mathrm{VI})$ & 44 \\
\hline PEI-GO & Not mentioned & $\mathrm{Cr}(\mathrm{VI})$ & 25 \\
\hline GO- $\alpha \mathrm{CD}$ & Not mentioned & $\mathrm{Cr}(\mathrm{VI})$ & 45 \\
\hline MCGN & Not mentioned & $\mathrm{Cr}(\mathrm{VI})$ & 46 \\
\hline
\end{tabular}

Table 1. Graphene oxide (GO) composite adsorbents synthesized using different GO drying processes.

(hydroxyl, epoxy, carbonyl and carboxyl groups) of GO facilitate the facile introduction of desired functional groups $^{22-27}$, which enable adsorbent applications for removal of harmful elements. Due to these properties, many GO composites have been studied for the adsorption of heavy metals (Table 1). Herein, when focusing on the GO state prior to the functionalization process, there were various GO conditions, including solution, freeze-drying, oven-drying, etc. and some studies had no mention of it.

Recently, we showed that the adsorbents synthesized by chemically bonding GO and amino-silanes have excellent performance in chromium adsorption $\left(260.74 \mathrm{mg} \mathrm{g}^{-1}\right)^{25}$. However, in the similar work by Janik et al. (2018), adsorbents have relatively low $\mathrm{Cr}(\mathrm{VI})$ adsorption capacities (13.3-15.1 $\mathrm{mg} \mathrm{g}^{-1}$ ) and the opposite order of Lee et al. (2020)' $\mathrm{s}^{28}$. The minor yet remarkable difference between these two studies, which many researchers overlooked, is the use of different approaches for the preparation of GO. While Janik et al. (2018) used the oven-drying of $\mathrm{GO}$ at $100^{\circ} \mathrm{C}$ (oven-dried GO (ODGO)) for preparation of GO, Lee et al. (2020) employed the solution form of GO (Solution-GO, SGO), which revealed the importance of adopting the appropriate drying process. As far as we know, there is no study suggesting suitable process of GO for surface functionalization so far.

Therefore, with an aim to find improved and effective processes for GO surface functionalization, we compared the differences in the $\mathrm{Cr}(\mathrm{VI})$ adsorption capacities caused by the variations in the conditions employed for the preparation of GO surfaces before the functionalization. We are certain that the results of this study will help researchers working with GO for the development of various applications.

\section{Results and discussion}

$\mathrm{Cr}(\mathrm{VI})$ adsorption isotherm on $\mathbf{G O}+\mathbf{3 N}$ adsorbents. The recorded adsorption isotherms describe the physicochemical adsorption resulting from the interaction between $\mathrm{Cr}(\mathrm{VI})$ and the adsorbent surfaces. The obtained equilibrium data was fitted to the Langmuir and Freundlich isotherm models. The Langmuir equilibrium adsorption isotherm describes the adsorption reaction of the monolayer on homogenous surfaces as a function of the partial pressure at constant temperature. The equation for the Langmuir adsorption isotherm is shown in Eq. 1.

$$
Q_{e}=\frac{K_{L} Q_{m} C_{e}}{1+K_{L} C_{e}}
$$

where $\mathrm{Q}_{\mathrm{e}}$ is the equilibrium adsorption capacity $\left(\mathrm{mg} \mathrm{g}^{-1}\right) ; \mathrm{Q}_{\mathrm{m}}$ is the maximum adsorption capacity on the adsorbent surface of the monolayer $\left(\mathrm{mg} \mathrm{g}^{-1}\right)$; $\mathrm{C}_{\mathrm{e}}$ is the equilibrium concentration of $\mathrm{Cr}(\mathrm{VI})\left(\mathrm{mg} \mathrm{L}^{-1}\right)$; and $\mathrm{K}_{\mathrm{L}}$ is the affinity constant $\left(\mathrm{L} \mathrm{mg}^{-1}\right)^{29-31}$.

Freundlich equilibrium adsorption isotherm describes the adsorption characteristics of the heterogeneous surface, which comprises the terminal and functional groups that offer stable binding sites. The Freundlich adsorption isotherm is an empirical equation and is represented by Eq. 2 .

$$
Q_{e}=K_{F} C_{e}^{1 / n}
$$

where $\mathrm{Q}_{\mathrm{e}}$ is the equilibrium adsorption capacity $\left(\mathrm{mg} \mathrm{g}^{-1}\right) ; \mathrm{K}_{\mathrm{F}}$ is the Freundlich constant related to adsorption capacity $\left(\mathrm{mg} \mathrm{g}^{-1}\right) ; \mathrm{n}$ is the adsorption intensity.

The experimental results were fitted using Eqs. 1 and 2 described above. As shown in Fig. 1, the points and nonlinear curves were well matched. The last point in the Langmuir fitting (Fig. 1(a)) indicated that it was 

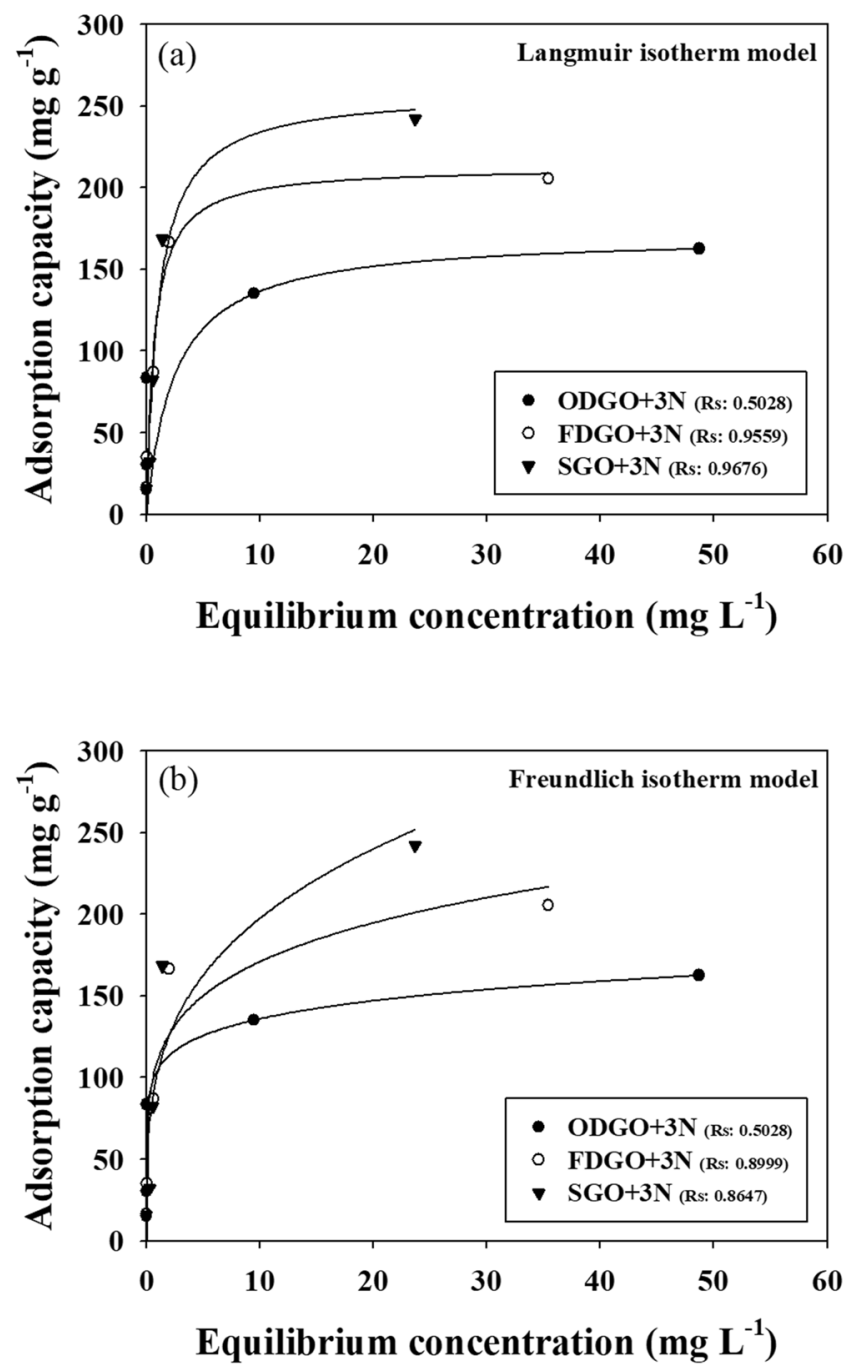

Figure 1. $\mathrm{Cr}(\mathrm{VI})$ adsorption isotherms for $\mathrm{GO}+3 \mathrm{~N}$ adsorbents: (a) Langmuir isotherm model and (b) Freundlich isotherm model.

nearly in equilibrium. A comparison of the two models revealed that the Langmuir model showed relatively high regression coefficients (R square, Rs), whereas the Freundlich model showed low Rs values because of the high concentration results, indicating that the Langmuir model was relatively better in describing the adsorption capacities. These results confirmed that the surfaces of the adsorbents were homogeneous, and adsorption reactions occurred well in the monolayer. On the other hand, the isotherm models for ODGO $+3 \mathrm{~N}$ did not fit the equilibrium adsorption data well, due to the poor fit of the third point of the result.

Characterization. Figure 2 shows XPS analysis after amine functionalization of the samples. It proved that amino silanes were successfully functionalized on the GO surface regardless of dry process. In adsorbents, the binding energies of Si atom were detected at around $153 \mathrm{eV}$ (Si 2s) and $103 \mathrm{eV}$ (Si 2p). Also, the peak of N $1 \mathrm{~s}$ at around $400 \mathrm{eV}$ was confirmed ${ }^{32}$. Table 2 shows a comparison of the $\mathrm{Cr}(\mathrm{VI})$ maximum adsorption capacities of the adsorbents that were prepared by the different functionalization processes and showed a significant difference in adsorption capacities. SGO prepared without the drying process recorded the highest $\mathrm{Cr}(\mathrm{VI})$ adsorption capacity of $258.48 \mathrm{mg} \mathrm{g}^{-1}$, while ODGO dried at $70{ }^{\circ} \mathrm{C}$ in air showed the worst capacity of $173.45 \mathrm{mg} \mathrm{g}^{-1}$. The $\mathrm{Cr}(\mathrm{VI})$ adsorption capacity of FDGO was $212.46 \mathrm{mg} \mathrm{g}^{-1}$ and was in-between the values for the other two samples. The values for the $1 / \mathrm{n}$ data also showed the orders of adsorption for SGO, FDGO and ODGO. The larger the $1 / \mathrm{n}$ values, the greater is the adsorption. The data for the maximum adsorption capacities and $1 / \mathrm{n}$ values were therefore in agreement and indicate that the process is critical for imparting adsorption capacity to GO. During the functionalization process, the molecules used, access, react, and bind to the oxygen on the GO surface. The differences in the performances of the GO samples are expected to originate from the differences in the accessibility of the functionalized molecules to the $\mathrm{Cr}(\mathrm{VI})$ species; i.e., the overlapping of GO layers could contribute to the differences in the accessibility of the molecules to GO surface. To verify this hypothesis, the following additional analyses were carried out. 


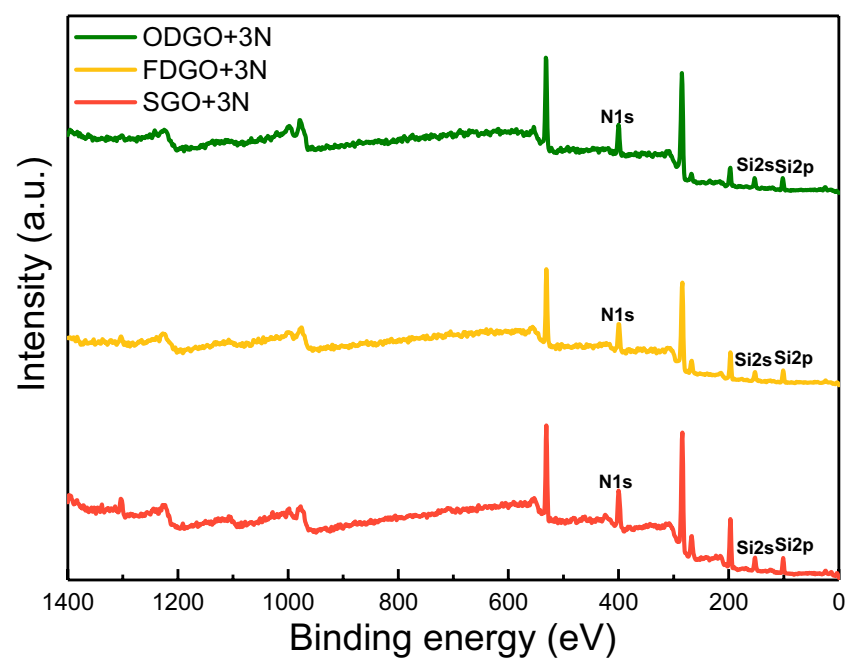

Figure 2. XPS survey scans of ODGO $+3 \mathrm{~N}, \mathrm{FDGO}+3 \mathrm{~N}$ and $\mathrm{SGO}+3 \mathrm{~N}$.

\begin{tabular}{|l|l|l|l|}
\hline & SGO +3N & FDGO + 3N & ODGO + 3N \\
\hline $\mathrm{Q}_{\mathrm{m}}\left(\mathrm{mg} \mathrm{g}^{-1}\right)$ & 258.48 & 212.46 & 173.45 \\
\hline $1 / \mathrm{n}$ & 0.2807 & 0.1874 & 0.1120 \\
\hline
\end{tabular}

Table 2. $\mathrm{Cr}(\mathrm{VI})$ adsorption capacities of $\mathrm{GO}+3 \mathrm{~N}$ adsorbents.

Figure 3(a,b) show the same amount of GO samples, which were prepared with different processes, and indicate a huge volume difference. FDGO had a much larger volume than ODGO. Further, SEM observations confirmed that the overlapping of GO layers is much more extensive in ODGO than FDGO (Fig. 3(c,d)). The layers of FDGO were well dispersed and enabled the visualization of the transparent GO layers and their wrinkles, whereas the layers of ODGO were multiply stacked and formed particles, which might have resulted in the exposed surface being smaller. The BET analysis results supported this observation. The surface area of ODGO was 2.9587 $\mathrm{m}^{2} \mathrm{~g}^{-1}$, which is significantly lower than the $24.139 \mathrm{~m}^{2} \mathrm{~g}^{-1}$ of FDGO (Table S1 in Supporting Information). In summary, oven-drying resulted in low dispersion of the GO layer, thereby reducing the accessible surface area. Next, we turned our attention to confirm that the reduction in the accessible surface area influenced the degree of functionalization, which is directly related to the adsorption performance.

To quantify the degree of functionalization, we conducted a TG analysis. TGA residual after heating up to $800^{\circ} \mathrm{C}$ is the amount of $\mathrm{SiO}_{2}$, indicates that of functionalizing amino-silane on each $\mathrm{GO}$ adsorbent (Table 3). The residue obtained for $\mathrm{SGO}+3 \mathrm{~N}$ was the largest and was followed by FDGO $+3 \mathrm{~N}$ and ODGO $+3 \mathrm{~N}$ (Figure S1). Furthermore, the XPS analysis results were consistent with the TG results. The XPS atomic concentration results of $\mathrm{Si} / \mathrm{C}$ and N/C indicated that the SGO $+3 \mathrm{~N}$ contained the highest concentration of the amine functional groups on the surface. The TGA and XPS results have fewer differences than those of the BET surface area because the overlapped GO layers of ODGO might be dispersed further to some extent.

Elemental analysis was conducted to determine if the reduction of the exposed surface area was the only cause of performance degradation. The EA results presented in Table 4 confirm that the oxygen content was reduced due to partial reduction of the exposed surface area during the drying process, and was significantly lower in ODGO. This means that $-\mathrm{COOH}$ and $-\mathrm{OH}$ functional groups, which are necessary for functionalization, were reduced during the drying process, thus decreasing the density of silane-functionalization. These studies reveal that despite using the same GO source, variations in the drying processes cause the differences in the density of sites for silane-functionalization, as well as influence the effective surface area. In summary, the degradation of adsorption performance can be attributed to the physical changes, loss of effective GO surface area, the ensuing chemical changes, and the reduction of GO.

\section{Conclusions}

The studies revealed that avoiding drying process is the most effective approach for ensuring suitable surface functionalization of GO. This is not only because the dispersion of GO layers can be maintained and the effective exposure surface area can be extensive by avoiding the drying process, but the reduction of GO can be suppressed. More importantly, the drying method makes a significant difference in the GO surface state. If the drying process is inevitable, freeze-drying is recommended rather than oven-drying. General oven-drying has a negative effect on the GO's performance, caused by the overlapping of GO layers and the reduction of GO. It is confirmed that freeze-drying causes less overlapping and lower loss of oxygen-containing surface functional groups, which act as bonding-sites for silane-functionalization. In this paper, we suggest suitable processes for the treatment of GO with systematic experiments and analysis, which will aid better functionalization and development of GO-based catalysts. 


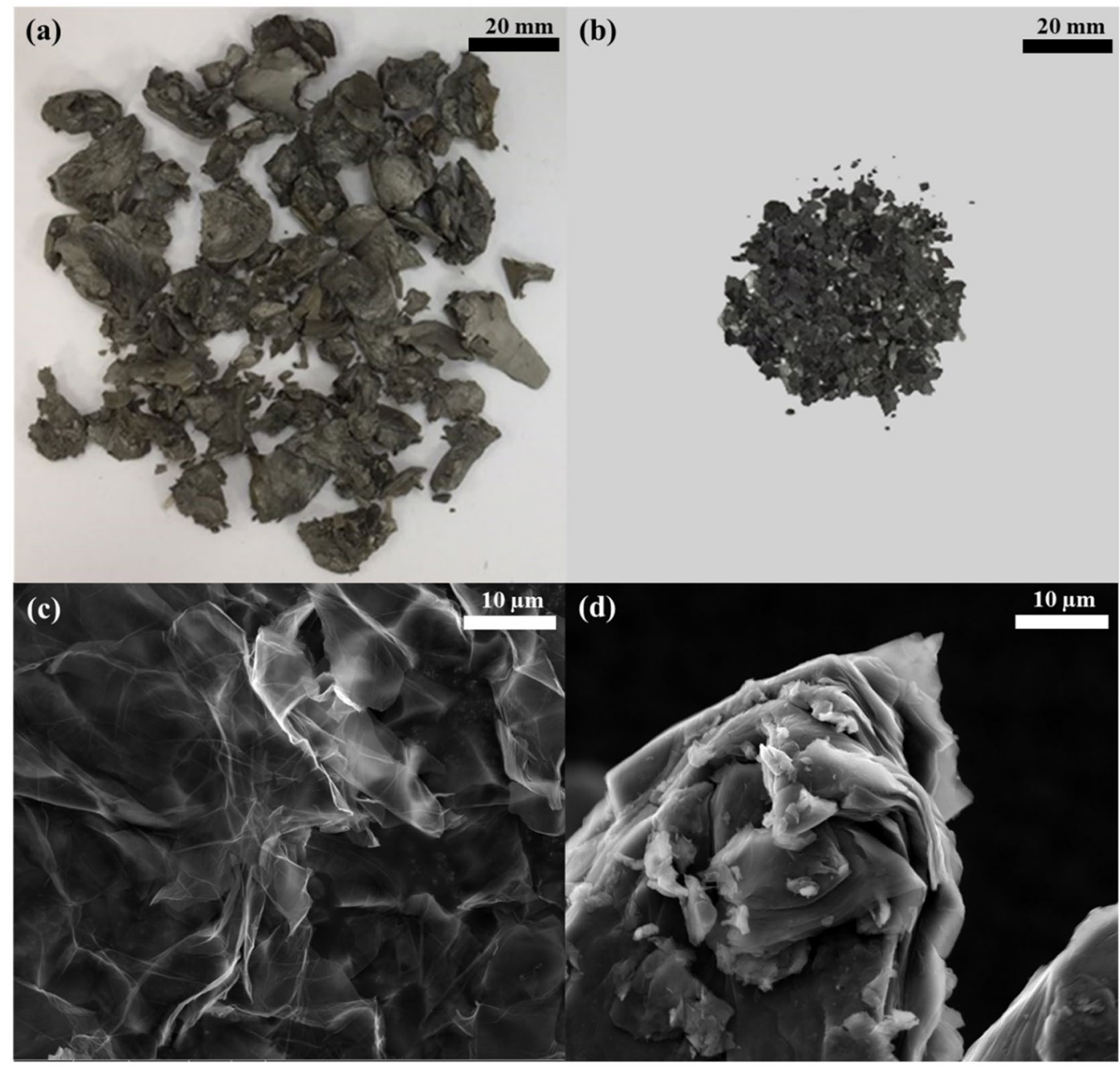

Figure 3. Optical images of (a) FDGO and (b) ODGO (200 mg) and SEM micrographs of (c) FDGO and (d) ODGO.

\begin{tabular}{|l|l|l|l|}
\hline & TGA residual (\%) & N/C & Si/C \\
\hline SGO + 3N & 20.42 & 0.205 & 0.089 \\
\hline FDGO + 3N & 16.24 & 0.179 & 0.074 \\
\hline ODGO + 3N & 12.66 & 0.155 & 0.072 \\
\hline
\end{tabular}

Table 3. Atomic concentration results from TGA and XPS.

\begin{tabular}{|l|l|l|l|}
\hline & GO dried at $25^{\circ} \mathrm{C}$ & FDGO & ODGO \\
\hline O/C ratio & 0.74 & 0.68 & 0.59 \\
\hline
\end{tabular}

Table 4. Elemental analysis.

\section{Materials and methods}

Materials. Graphene oxide (GO)-V50 was purchased from Standard Graphene. 3-[2-(2-aminoethylamino) ethylamino]propyl-trimethoxysilane (AEAEAPTMS, technical grade), methanol ( $\geq 99.9 \%)$, and $\mathrm{Cr}$ (VI) stock solution dissolving potassium chromate $\left(\mathrm{K}_{2} \mathrm{Cr}_{2} \mathrm{O}_{7}, 99.5 \%\right)$ in $0.01 \mathrm{M}$ nitric acid $\left(\mathrm{HNO}_{3}\right)$ were obtained from Sigma-Aldrich and Kanto chemical.

Synthesis of 3N-GO-adsorbents. Scheme 1 shows the overall processes used for the adsorbent synthesis and summarizes the differences by the process. GO-V50 was functionalized with AEAEAPTMS using a slight modification of a reported method ${ }^{10,33,34}$, and 3 types of GO-V50 were prepared. The first was prepared in the solution form, the second was prepared by freeze-drying, and the final was by oven-drying at $70^{\circ} \mathrm{C}$ Each of 




Scheme 1. Flowchart of the synthesis of $\mathrm{GO}+3 \mathrm{~N}$ adsorbents.

these suspensions $\left(0.5 \mathrm{~g}\right.$ of $\mathrm{GO} / 140 \mathrm{~mL}$ of methanol) was sonicated for $2 \mathrm{~h}$ and refluxed at $60^{\circ} \mathrm{C}$ with stirring at $1000 \mathrm{rpm}$. At $60^{\circ} \mathrm{C}$, AEAEAPTMS $(5 \mathrm{~mL})$ was added to each suspension. After a $24 \mathrm{~h}$ reaction, the product was washed with ethanol using centrifugation at 13,500 rpm for $12 \mathrm{~min}$ three times. Each washed sample of AEAEAPTMS-GO (3N-GO) was dried at $40^{\circ} \mathrm{C}$ overnight. Lastly, the products were treated with $0.1 \mathrm{M} \mathrm{HCl}$ for $6 \mathrm{~h}$ and were collected by centrifugation and dried at $40^{\circ} \mathrm{C}$ overnight.

Equilibrium adsorption of $\mathrm{Cr}(\mathrm{VI})$ on GO-adsorbents. We acquired the $\mathrm{Cr}(\mathrm{VI})$ adsorption isotherms of five samples of $\mathrm{Cr}(\mathrm{VI})$ solutions of concentrations $5,10,25,50,100 \mathrm{mg} \cdot \mathrm{L}^{-1}$. The three samples (15 $\mathrm{mg}$ each) of the adsorbents which were prepared by drying at $70^{\circ} \mathrm{C}$, freeze-drying, and as a GO solution, respectively, and were injected into each of the five $\mathrm{Cr}(\mathrm{VI})$ solutions and were reacted for $24 \mathrm{~h}$ at $25 \mathrm{rpm}$ using a rotator. Upon reaction completion, the solution was centrifuged at $4200 \mathrm{rpm}$ for solid-liquid separation, and the mixture was filtered using a $0.2 \mu \mathrm{m}$ PVDF syringe filter for completely separating the solution from the adsorbents.

Scanning electron microscopy (SEM). The morphology of GO samples was analyzed by scanning electron microscopy (SEM, FEI Inspect F50, AP-tech Company).

Brunauer-Emmett-Teller (BET). The specific surface area was determined from the linear portion of BET plots $\left(\mathrm{P} / \mathrm{P}_{0}=0\right.$ to 1$)$, which were acquired using a surface area analyzer (BEL-SORP-max, BEL Japan Inc., Japan).

Thermogravimetric analysis (TGA). Thermogravimetric analysis (TGA, N-1500, Scinco) of the $\mathrm{GO}$-adsorbents was performed to confirm the amount of aminosilanes grafted onto the GO surface by heating the adsorbents from 100 to $800^{\circ} \mathrm{C}$ at a rate of $10^{\circ} \mathrm{C} \mathrm{min}-1$ under air condition.

X-ray photoelectron spectroscopy (XPS). X-ray photoelectron spectroscopy (XPS, PHI 5000 VersaProbe Ulvac-PHI with Al X-ray monochromatic source ( $\mathrm{Al} \mathrm{K} \mathrm{K}_{\alpha}$ source with energy $1486.6 \mathrm{eV}$ at $\left.24.5 \mathrm{~W}\right)$, Physical Electronics Inc.) analysis was performed to determine the surface composition of the adsorbents. The binding energies were referenced to the $\mathrm{C} 1 \mathrm{~s}$ line at $284.6 \mathrm{eV}$ from the adventitious carbon.

Elemental analysis (EA). The elemental ratio (O/C ratio) of GO was obtained from elemental analysis (EA, FLASH 2000, Thermo Scientific). The average values of $2 \sim 3$ measurements were used as the data.

Inductively coupled plasma optical emission spectrometer (ICP-OES). An inductively coupled plasma optical emission spectrometer (ICP-OES, ProdigyPlus, Prodigy) and an autosampler were used for the quantitative analysis of the $\mathrm{Cr}(\mathrm{VI})$ solution before and after the reaction. Each sample was analyzed with 4 replicates, and the results were interpreted as the average value.

\section{Data availability}

All data generated and/or analyzed during this study are included in this published article.

Received: 4 January 2020; Accepted: 2 March 2020;

Published online: 17 March 2020

\section{References}

1. Vakili, M. et al. Novel crosslinked chitosan for enhanced adsorption of hexavalent chromium in acidic solution. Chem. Eng. J. 347, 782-790 (2018).

2. Enniya, I., Rghioui, L. \& Jourani, A. Adsorption of hexavalent chromium in aqueous solution on activated carbon prepared from apple peels. Sustain. Chem. Pharm. 7, 9-16 (2018).

3. Islam, M. N., Khan, M. N., Mallik, A. K. \& Rahman, M. M. Preparation of bio-inspired trimethoxysilyl group terminated poly(1vinylimidazole)-modified-chitosan composite for adsorption of chromium (VI) ions. J. Hazard. Mater. 379, 120792 (2019).

4. Khosravi, R. et al. Chromium adsorption from aqueous solution using novel green nanocomposite: Adsorbent characterization, isotherm, kinetic and thermodynamic investigation. J. Mol. Liq. 256, 163-174 (2018).

5. Adio, S. O. et al. Poly (amidoxime) modified magnetic activated carbon for chromium and thallium adsorption: Statistical analysis and regeneration. Process Saf. Environ. Prot. 121, 254-262 (2019).

6. Wang, H. et al. Facile synthesis of polypyrrole decorated reduced graphene oxide-Fe3O4 magnetic composites and its application for the Cr(VI) removal. Chem. Eng. J. 262, 597-606 (2015).

7. Sheikhmohammadi, A. et al. Application of graphene oxide modified with the phenopyridine and 2-mercaptobenzothiazole for the adsorption of $\mathrm{Cr}$ (VI) from wastewater: Optimization, kinetic, thermodynamic and equilibrium studies. J. Mol. Liq. 285, 586-597 (2019). 
8. Ihsanullah et al. Heavy metal removal from aqueous solution by advanced carbon nanotubes: Critical review of adsorption applications. Sep. Purif. Technol. 157, 141-161 (2016).

9. Geng, J., Yin, Y., Liang, Q., Zhu, Z. \& Luo, H. Polyethyleneimine cross-linked graphene oxide for removing hazardous hexavalent chromium: Adsorption performance and mechanism. Chem. Eng. J. 361, 1497-1510 (2019).

10. Janik, P., Zawisza, B., Talik, E. \& Sitko, R. Selective adsorption and determination of hexavalent chromium ions using graphene oxide modified with amino silanes. Microchim. Acta 185 (2018).

11. $\mathrm{Xu}$, C. et al. Preparation and characterization of $\beta-\mathrm{FeOOH}$-coated sand and its adsorption of $\mathrm{Cr}(\mathrm{VI})$ from aqueous solutions. Front. Environ. Sci. Eng. China 6, 455-462 (2012).

12. Fang, Y. et al. Effect of mineralizing agents on the adsorption performance of metal-organic framework MIL-100(Fe) towards chromium(VI). Chem. Eng. J. 337, 532-540 (2018).

13. Huang, X. et al. Effective removal of $\mathrm{Cr}(\mathrm{VI})$ using $\beta$-cyclodextrin-chitosan modified biochars with adsorption/reduction bifuctional roles. RSC Adv. 6, 94-104 (2015).

14. Sherlala, A. I. A., Raman, A. A. A., Bello, M. M. \& Asghar, A. A review of the applications of organo-functionalized magnetic graphene oxide nanocomposites for heavy metal adsorption. Chemosphere 193, 1004-1017 (2018).

15. Zhao, D. et al. Facile preparation of amino functionalized graphene oxide decorated with $\mathrm{Fe}_{3} \mathrm{O}_{4}$ nanoparticles for the adsorption of Cr(VI). Appl. Surf. Sci. 384, 1-9 (2016).

16. Fu, F. \& Wang, Q. Removal of heavy metal ions from wastewaters: A review. J. Environ. Manage. 92, 407-418 (2011).

17. Sheikhmohammadi, A. et al. The synthesis and application of the Fe3O4@SiO2 nanoparticles functionalized with 3 -aminopropyltriethoxysilane as an efficient sorbent for the adsorption of ethylparaben from wastewater: Synthesis, kinetic, thermodynamic and equilibrium studies. J. Environ. Chem. Eng. 7 (2019).

18. Chang, H. \& Wu, H. Graphene-based nanocomposites: Preparation, functionalization, and energy and environmental applications. Energy Environ. Sci. 6, 3483-3507 (2013).

19. Peng, W., Li, H., Liu, Y. \& Song, S. A review on heavy metal ions adsorption from water by graphene oxide and its composites. J. Mol. Liq. 230, 496-504 (2017).

20. Wang, X., Liu, B., Lu, Q. \& Qu, Q. Graphene-based materials: Fabrication and application for adsorption in analytical chemistry. J. Chromatogr. A 1362, 1-15 (2014).

21. Dinda, D., Gupta, A. \& Saha, S. K. Removal of toxic Cr(vi) by UV-active functionalized graphene oxide for water purification. J. Mater. Chem. A 1, 11221-11228 (2013).

22. Sitko, R., Zawisza, B. \& Malicka, E. Graphene as a new sorbent in analytical chemistry. TrAC - Trends Anal. Chem. 51, 33-43 (2013).

23. Duru, İ., Ege, D. \& Kamali, A. R. Graphene oxides for removal of heavy and precious metals from wastewater. J. Mater. Sci. 51, 6097-6116 (2016).

24. Najafabadi, H. H., Irani, M. \& Rad, R. RSC Advances composite nano fi brous adsorbent. 16532-16539, https://doi.org/10.1039/ c5ra01500f (2015).

25. Chen, J. H. et al. Investigation on the adsorption properties of $\mathrm{Cr}(\mathrm{vi})$ ions on a novel graphene oxide (GO) based composite adsorbent. J. Mater. Chem. A 2, 12561-12570 (2014).

26. Wei, H., Zhu, J., Wu, S., Wei, S. \& Guo, Z. Electrochromic polyaniline/graphite oxide nanocomposites with endured electrochemical energy storage. Polymer (Guildf). 54, 1820-1831 (2013).

27. Sheikhmohammadi, A. et al. Fabrication of magnetic graphene oxide nanocomposites functionalized with a novel chelating ligand for the removal of $\mathrm{Cr}(\mathrm{VI})$ : Modeling, optimization, and adsorption studies. Desalin. Water Treat. 160, 297-307 (2019).

28. Lee, J. et al. Most suitable amino silane molecules for surface functionalization of graphene oxide toward $\mathrm{Cr}(\mathrm{VI})$ adsorption. Chemosphere (2020).

29. Hong, M. et al. Heavy metal adsorption with zeolites: The role of hierarchical pore architecture. Chem. Eng. J. 359, 363-372 (2019).

30. Wu, Y. et al. Environmental remediation of heavy metal ions by novel-nanomaterials: A review. Environ. Pollut. 246, 608-620 (2019).

31. Zhao, B. et al. Preparation of acrylamide/acrylic acid cellulose hydrogels for the adsorption of heavy metal ions. Carbohydr. Polym. 224, $115022(2019)$.

32. Gun, Y., Jeong, H., Chul, H. \& Su, U. Amines immobilized double-walled silica nanotubes for CO 2 capture. J. Hazard. Mater. 250-251, 53-60 (2013).

33. Yoshitake, H., Yokoi, T. \& Tatsumi, T. Adsorption of Chromate and Arsenate by Amino-Functionalized MCM-41 and SBA-1, 4603-4610 https://doi.org/10.1021/cm0202355 (2002).

34. Zhang, F., Jiang, H., Li, X., Wu, X. \& Li, H. Amine-Functionalized GO as an Active and Reusable Acid - Base Bifunctional Catalyst for One-Pot Cascade Reactions. https://doi.org/10.1021/cs400761r (2014).

35. Guo, F. Y. et al. Adsorption behavior of $\mathrm{Cr}(\mathrm{vi})$ from aqueous solution onto magnetic graphene oxide functionalized with 1,2-diaminocyclohexanetetraacetic acid. RSC Adv. 5, 45384-45392 (2015).

36. Luo, S. et al. Amino siloxane oligomer-linked graphene oxide as an efficient adsorbent for removal of $\mathrm{Pb}$ (II) from wastewater. J. Hazard. Mater. 274, 145-155 (2014).

37. Xu, Z. et al. One step synthesis of polyacrylamide functionalized graphene and its application in $\mathrm{Pb}$ (II) removal. Appl. Surf. Sci. 316, 308-314 (2014).

38. Kumar, A. S. K., Kakan, S. S. \& Rajesh, N. A novel amine impregnated graphene oxide adsorbent for the removal of hexavalent chromium. Chem. Eng. J. 230, 328-337 (2013).

39. Jiao, C. et al. Sodium alginate/graphene oxide aerogel with enhanced strength-toughness and its heavy metal adsorption study. Int. J. Biol. Macromol. 83, 133-141 (2016).

40. Ghiasvand, A., Behfar, M. \& Yazdankhah, F. Polypyrrole/graphene oxide nanocomposite-coated fiber located in a capillary tube reinforced by a vacuum system for assessment of oxidative stability of edible oils. U.S. Pat. 1 (2019).

41. Awad, F. S., Abouzeid, K. M., El-Maaty, W. M. A., El-Wakil, A. M. \& El-Shall, M. S. Efficient removal of heavy metals from polluted water with high selectivity for mercury(II) by 2-imino-4-thiobiuret-partially reduced graphene oxide (IT-PRGO). ACS Appl. Mater. Interfaces $9,34230-34242$ (2017).

42. Setshedi, K. Z., Bhaumik, M., Onyango, M. S. \& Maity, A. High-performance towards Cr(VI) removal using multi-active sites of polypyrrole-graphene oxide nanocomposites: Batch and column studies. Chem. Eng. J. 262, 921-931 (2015).

43. Marwani, H. M., Albishri, H. M., Soliman, E. M. \& Jalal, T. A. Selective adsorption and determination of hexavalent chromium in water samples by chemically modified activated carbon with tris(hydroxymethyl)aminomethane. J. Dispers. Sci. Technol. 33, $549-555$ (2012)

44. Ge, H. \& Ma, Z. Microwave preparation of triethylenetetramine modified graphene oxide/chitosan composite for adsorption of Cr(VI). Carbohydr. Polym. 131, 280-287 (2015).

45. Chauke, V. P., Maity, A. \& Chetty, A. High-performance towards removal of toxic hexavalent chromium from aqueous solution using graphene oxide-alpha cyclodextrin-polypyrrole nanocomposites. J. Mol. Liq. 211, 71-77 (2015).

46. Fan, L., Luo, C., Sun, M. \& Qiu, H. Synthesis of graphene oxide decorated with magnetic cyclodextrin for fast chromium removal. J. Mater. Chem. 22, 24577-24583 (2012). 


\section{Acknowledgements}

This study was supported by KIST institutional program (No. 2E30710) and the Technology Innovation Program (10082572, Development of Low Energy Desalination Water Treatment Engineering Package System for Industrial Recycle Water Production) funded by the Ministry of Trade, Industry \& Energy (MOTIE, Korea).

\section{Author contributions}

J.Lee, H.G. Kim, J.H. Lee and K.W. Jung performed the experiments and analyzed the data. S.H. Cho, S.Y. Lee and J.W. Choi conceived and designed the simulations and the experiments. J.Lee and H.G. Kim wrote the paper. S.Y. Lee and J.W. Choi reviewed and revised the overall manuscript.

\section{Competing interests}

The authors declare no competing interests.

\section{Additional information \\ Supplementary information is available for this paper at https://doi.org/10.1038/s41598-020-61760-2.}

Correspondence and requests for materials should be addressed to S.Y.L. or J.-W.C.

Reprints and permissions information is available at www.nature.com/reprints.

Publisher's note Springer Nature remains neutral with regard to jurisdictional claims in published maps and institutional affiliations.

(c) (i) Open Access This article is licensed under a Creative Commons Attribution 4.0 International License, which permits use, sharing, adaptation, distribution and reproduction in any medium or format, as long as you give appropriate credit to the original author(s) and the source, provide a link to the Creative Commons license, and indicate if changes were made. The images or other third party material in this article are included in the article's Creative Commons license, unless indicated otherwise in a credit line to the material. If material is not included in the article's Creative Commons license and your intended use is not permitted by statutory regulation or exceeds the permitted use, you will need to obtain permission directly from the copyright holder. To view a copy of this license, visit http://creativecommons.org/licenses/by/4.0/.

(c) The Author(s) 2020 